\title{
DESIGN OF STTAL COLLEGE STUDENT FINAL TASK AND RESEARCH PRODUCT INFORMATION SYSTEM BASED ON WEB
}

\author{
Ahmadi, Muchammadil Chafid, Alexander Victor Bukit, Arie Marbandi \\ Indonesian Naval Technology College, STTAL \\ Bumimoro-Moro Krembangan, Surabaya, 60178, Indonesia
}

\begin{abstract}
STTAL is an educational institution to improve the student capability in managing naval technology. Annually, STTAL graduates diplomas and produces final task from the research of students. This product will then be exhibited at official exhibitions of the Indonesian Navy. The information system is designed for the final project and research of STTAL students. This information system is web-based to facilitate the information about the tools that are displayed and will help exhibition crews in conveying information about the tools to the visitors. This information system is easy to use, by scanning the $Q R$ Code on the device by Android smartphone application.
\end{abstract}

Keywords : STTAL student work, Final Project Product Information System and STTAL Student Research Based on Web, Android Smartphone, QR Code.

\section{INTRODUCTION}

\subsection{Background}

The Naval College of Technology (STTAL) is an educational institution to increase learning resources and understanding in information technology management capabilities for Indonesian Navy. Most of the soldiers who graduated from STTAL are capable of making, building, and designing information tools and systems that can later be used as guidelines in supporting work tasks both in the field and in the manpower service.

For example, we can see the results of design and research by STTAL students at the STTAL student graduation event exhibition, STTAL Anniversary, Naval Education Anniversary, Armada Anniversary, and many other official events. The work of STTAL students is exhibited and exhibited at these events. For the STTAL campus environment, the design and research results of STTAL students are stored and displayed in the lobby of the building.

To support the understanding of the members who are assigned to guard the tools displayed by STTAL students, this information system designed as the student can convey the information to visitors. From here, the Naval College of Technology (STTAL) needs the support of an information technology system to support the delivery of information quickly, precisely and independently to visitors who come and visit the STTAL campus.

In response to this problem, the design of information system is to fulfil STTAL's needs.
This design aims to provide information about the design work and research of STTAL students to visitors both on work visits and at official exhibition events. This information system is planned to be easily accessible because it is web-based and also supports installation on smartphone (android) devices. This design is expected to be able to help support the personnel manning the tools on display in providing explanations to visitors who come to the STTAL campus and at the Indonesian Navy official exhibition event.

\subsection{Problem Formulation}

Based on the description from the background, problem formulations are occurred when there are exhibitions and work visits at STTAL. How to make an information system about the results of STTAL student products and research that can be accessed quickly and easily by users or visitors at exhibition events??

\subsection{Research Objectives}

The purpose of the information system design is to build an information system in STTAL final task and research product based on Web that will be used in an exhibition.

\subsection{Research Benefits \\ The benefits of the research are as} follows:

a. To support the staff of study program to monitor the research product of college student.

b. To support the STTAL personnel to deliver information about the research product of college student. 
c. To give accurate information for exhibition visitor instantly.

\subsection{Scope of Problem}

In solving the problem of this Monitoring System Plan, limitations are needed to overcome the problem with the aim of facilitating the planning process by emphasizing the subject for better. Limitation problems in this study are:

a. The data used in this information system research is taken at the STTAL Education Institute and the data inputted in this information system is the design and research work of STTAL students.

b. Information system that is built for all users or visitors during exhibitions and work visits at STTAL.

c. The system of STTAL student final assignments and research information will be turned off after the work visit and exhibition are over.

\subsection{Assumption}

The assumptions in this research are:

a. This information system is public so that users can access it in real time.

b. devices / devices to access the information system, in this case a smartphone with the android operating system, is connected to the internet network.

c. The procedure for use and information is very easy and what is displayed is in accordance with the QR code on the design device being scanned.

\section{LITERATURE REVIEW}

\subsection{Website}

A website is a web page that can be interconnected which generally contains a set of information such as text data, images, animation, audio, and video as well as a combination of some or all of which are usually used for personal, organizational and corporate purposes. From the definitions of the website, it can be divided into 3 , namely static, dynamic, and interactive. It is static if the content of the information is fixed and the information is only from the owner of the website page.

Meanwhile, a dynamic web is if the information content is not patent or constantly changing and can also be changed by the owner or user of the website. The interactive web is a website that can be said at this time is very popular. On this website users can directly interact and also exchange opinions about what is on their minds. Examples of static webs: company profile websites, examples of dynamic websites such as Facebook, Twitter, etc., while examples of interactive web forums and blogs.

\subsection{Internet}

Internet is (short for interconnectionnetworks) is all communication networks that use electronic media, which are interconnected using the Global Transmission Control Protocol / Internet Protocol Suite (TCP / IP) standard as a packet switching communication protocol to serve users around the world. The largest network series is called the internet. This way of connecting circuits with this rule is called internetworking ("networking").

Providing an overview of the definition of the internet in general, although this technology is a manifestation of a combination of the world's computer networks, the internet needs to be taken seriously as a repository of information (Lani Sidharta, 1996). The internet has become a potential resource of information for making system life easier. The presence of an internet has been able to change and give birth to other new life systems, or so-called virtual worlds. The world may bear an almost unmistakable resemblance to real life. what is done in the real world, can be done now in the virtual world. for example, business activities carried out by someone who uses internet technology.

\subsection{Quick Response Code (QR Code)}

QR Code or QR Code is one type of twodimensional barcode or often called a matrix code. This code was first developed by Danso Wave, a division of the Japanese company Denso Cooperation. QR codes were first introduced to the public in 1994. To read barcodes, a QR Scanner or QR Scanner application is needed. QR (Quick Response) or in Indonesian is a quick response used to convey information on the code quickly.

QR Code itself is called the evolution of barcode, from one dimension to two dimensions. Barcodes can only store information horizontally, while QR Codes can store information vertically and horizontally. That's why QR codes have a high capacity for data coding. QR codes can store all types of data such as numeric, alphabetical data, kanji, hana, symbols, hiragana, and even binary codes.

\subsection{QR Code Scanner}

Is the process of scanning, decoding and reading the contents of $2 \mathrm{D}$ barcodes such as 
QR codes, using a cell phone called mobile tagging. To be able to read QR codes, one must have a QR code scanner. After taking the image from the QR code, the application processes the code and translates it into readable text. The scanner application used in this study is the QR Code Scanner. The following is an example of a QR Code Scanner on an android smartphone based on Figure 2.1.

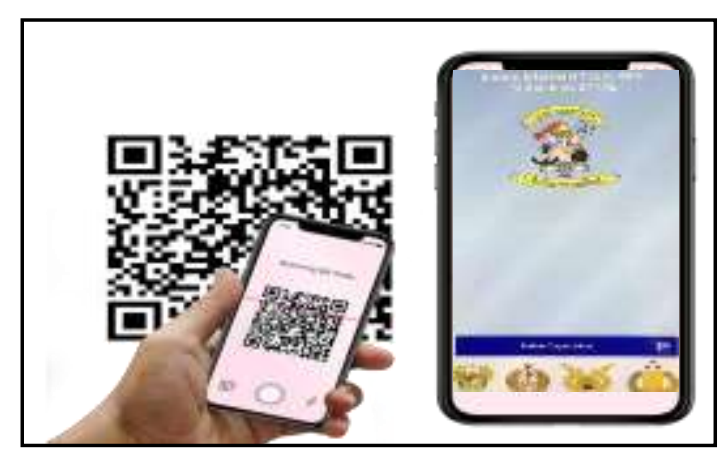

Figure 2.1 QR Code Scanner on Android

\section{RESEARCH METHOD}

\subsection{Research Design}

The research design can provide systematic directions or directions to researchers about the activities that must be carried out, when they will be carried out, and how to do them. The research design aims to carry out research in a systematic manner, to formulate hypotheses, so that conclusions can be drawn correctly according to the results of the analysis tools used.

Design Forms, models, experimental patterns: A series of activities to seek answers to problems by testing hypotheses (Alatas, 2011). Or: This series is an activity to monitor or observe the effect of $X$ on $Y$; where $X$ here is referred to as the treatment factor while $Y$ is referred to as the observation factor.

\subsection{Research Plan}

The design of this research is the stage where planning will be carried out after identifying problems and formulating problems in the field. This design aims to provide an overview of the course of the system of tools that will be made as a whole which aims to provide a clearer direction and targets to be achieved so that the research can go well in accordance with what is expected so that the process arrives with the objectives of the research in solving the problem can be worked out, clear and structured.
Figure 3.1 is an overview of the system as a whole as a user or visitor as a client in accessing information systems. As long as the user is in a position to request information from the system, the server will respond and send data to the user as desired, the data received periodically will be stored in the database server.

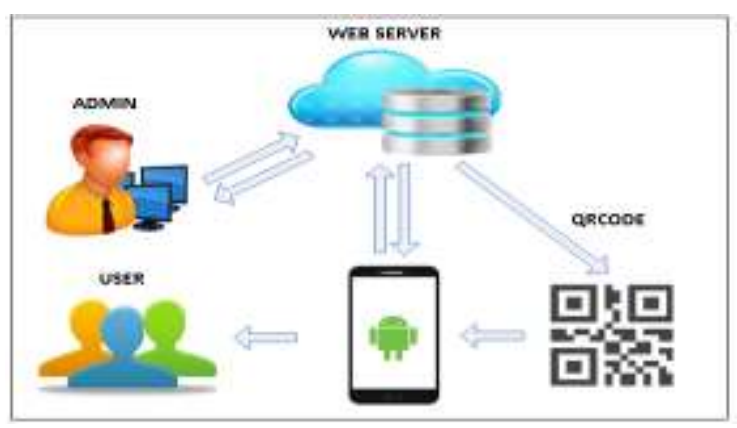

Figure 3.1 Overview of the System

\subsection{System Flowchart}

Flowchart aims as a way of presenting to explain an algorithm where the charts in it have a flow that aims to describe the steps of solving a problem. The purpose of making a flowchart is:

a. Describe the design and explain a stage for solving a problem in a simple, unraveled, neat and clear manner.

b. Using the technique of symbols or images that exist in the product information system of this final project and student-based STTAL research starting from data input via the web admin, then the data can be opened through an application on an Android smartphone by the user. The process flow of the STTAL student information system can be seen in Figure 3.2. 


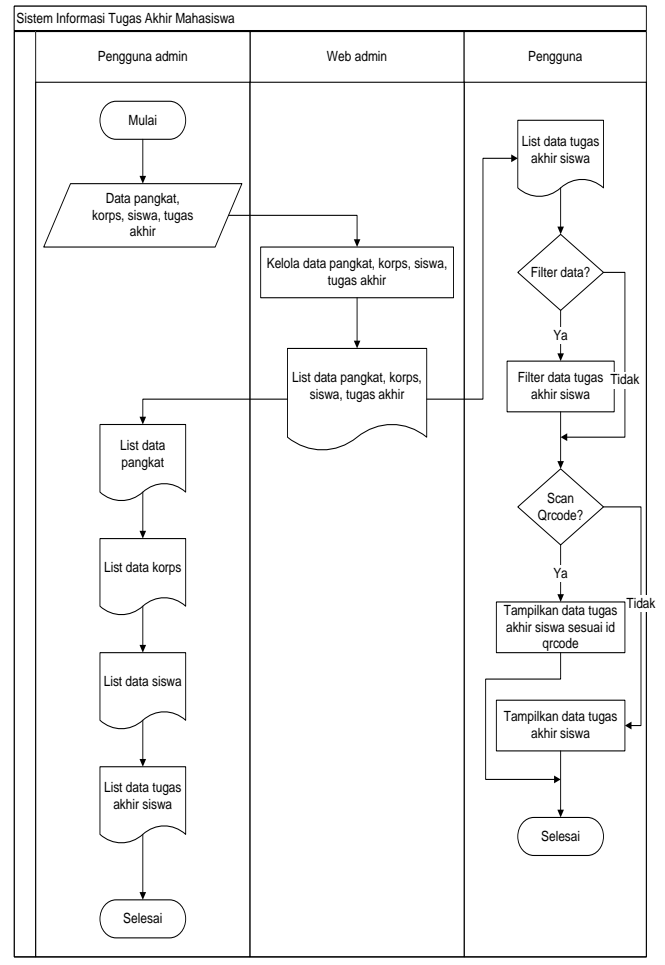

Figure 3.2 System Flow

\subsection{Document Flow}

Document Flow is the document flow of a system that is built. The process of processing data systems information systems for webbased STTAL student products and research can be illustrated in Figure 3.3. Where the admin who has processed data from the work of STTAL students until the user opens the information system application and uses the QR Code scanning facility available in the application.

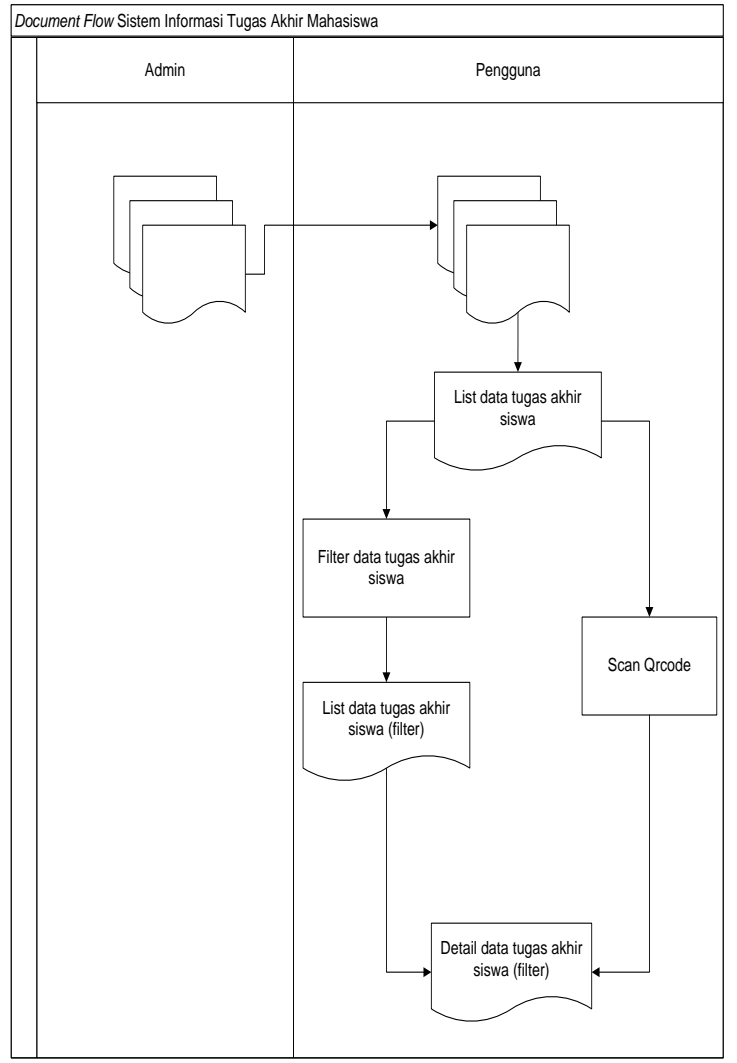

Figure 3.3 Document Flow System

\subsection{System Flowchart}

Database design is a process for determining the content and arrangement of the data needed as material to support the design of a system to be built. To support the Final Project Product Information System and Research.

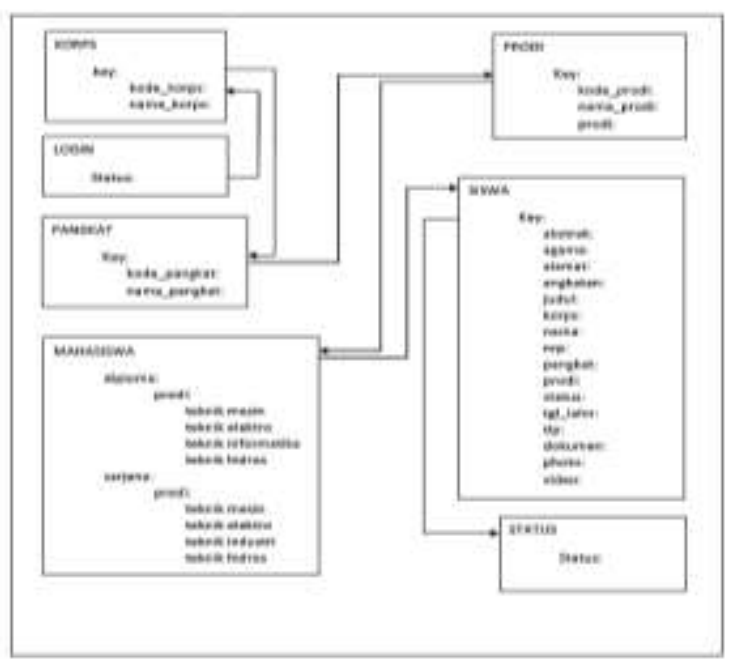

Figure 3.4 Database Design 


\section{ANALYSIS AND DISCUSSION}

\subsection{Anallysis}

In this final project research requires an analysis of the needs of the supporting components in designing a product information system for the final project and web-based STTAL student research that will be made. These components include human resource needs, information system requirements, hardware and software requirements as well as supporting data requirements. The research result is a re-examination of the validity of the research results.

In this final project research requires an analysis of the needs of the supporting components in designing a product information system for the final project and web-based STTAL student research that will be made. In this chapter, the writer will describe the analysis of the design and implementation as well as system testing in the final project information system design research and web-based STTAL student research.

\subsection{System Design}

The design of the information system in this student's final project needs to be analysed the system first by describing the design based on the needs needed in the system. The basis for system design refers to system requirements, so that system design can be carried out in accordance with the purpose of this system.

The design of the information system for student final assignments is a new system development, to meet the need for information on STTAL student final assignments that can be accessed and used as a source of information for visitors to the exhibition of the work of STTAL students.

In describing the design of the webbased STTAL student's final project information system design in general can be seen in Figure 4.1 below:

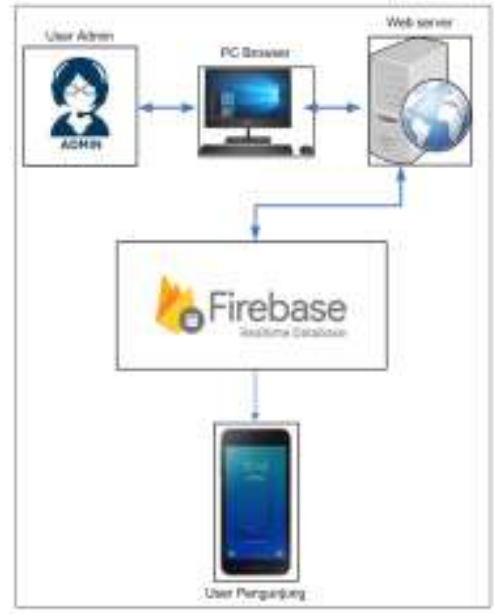

Figure 4.1 General Description of System
In Figure 4.1 an overview of the design of the Student Final Project Information System, it can be explained as follows:

a. Web server is an application that is used to run the web admin system. This application is placed on the htdocs server. The server used on the system is the Apache server integrated in the XAMPP program.

b. The firebase database serves to provide services in data storage in the database and image data storage and video file data in storage.

c. PC / Laptop web browser is a device for running web admin applications and accessed via a web browser.

d. The android application is used by visitors to access the student final project information system. Android devices are directly connected to the Firebase database.

In the admin web application, there are application features provided so that the admin user can perform data processing. Admin users can perform data processing with CRUD access (create, update, delete) data. The features planned for the web admin system design are as follows:

a. The student feature is a data processing feature for STTAL students.

b. The corps feature is a corps data processing feature.

c. The rank feature is a power data processing feature.

d. The feature of student work is a feature of processing student work data.

In the visitor's Android application, there are several features that can be accessed by users. These features can be described as follows.

a. The list feature of student work data is a feature to display student work in the form of a list view.

b. The detail feature of student work data is a feature to display details of student work. In the details of student work, there are detailed information about the student's work that has been made and accompanied by information on final project documentation pictures.

c. QR Code feature, a feature that can be used by users to scan the QR Code provided on each of the existing tools at the STTAL student exhibition booth. This feature can take the user directly to the detailed information of the final project that has been created. This feature provides image, video and document information in pdf format. 


\subsection{Student College Final Tash Information System Testing}

To test the Web-Based STTAL Product Information System and Student Research, the author prepares software or support programs in system testing as follows:

a. The apache server application uses XAMPP to run the admin web application.

b. Web browser, the author uses the chrome web browser application.

c. Install android applications intended for visitors.

In testing the web admin application, the author runs the web admin application on the Chrome web browser, by typing the application address into the Chrome address bar.

In the next figure the admin user or operator needs to log in to the system in order to use the features provided on the web page. To log in to the system the user must enter a username and password as shown in the system test image. If the user or operator has successfully logged in to the system according to the username and password that was created on the system, the admin page will be displayed. The following is the initial appearance of the web starting from the login to the menu page.

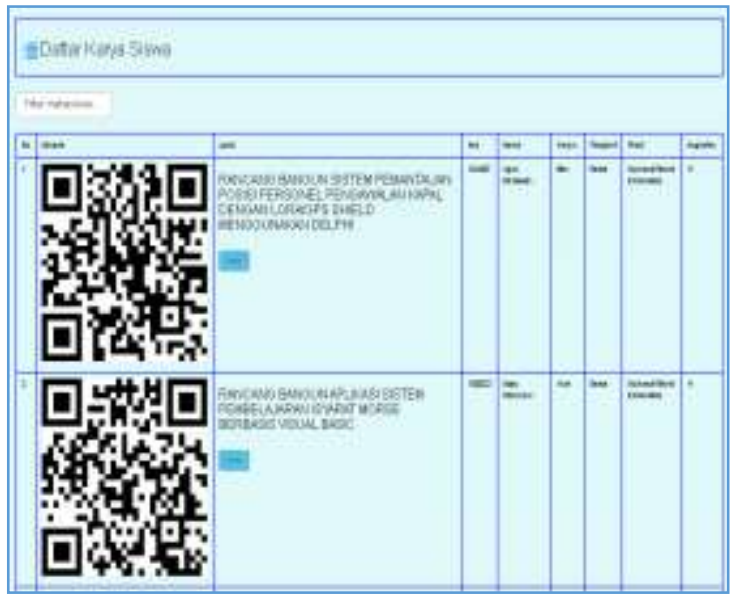

Figure 4.2 Aadministration Menu Page

On the admin page, the author tests each of the available features. In the following test the writer will test the admin web application on the student data feature.

In the next test the writer will test the student work page, the rank page is a page for managing student work data. On this page, admin users can add, change and delete detailed student work data. The following is a display of the student work data list page shown in the figure 4.3.

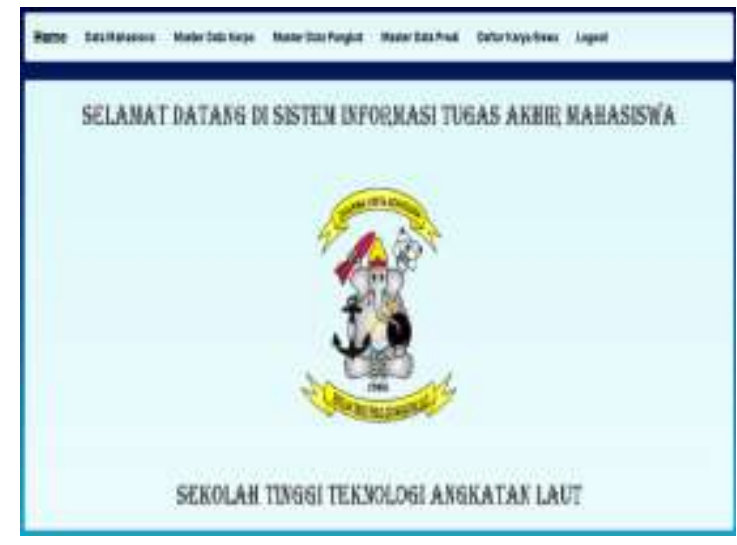

Figure 4.3 Tampilan Halaman List Data Karya Mahasiswa

In the next test, we will test the user application on the student data menu display that has been filtered according to each strata and study program. The following are the study programs at the STTAL S1 and D3 strata:

a. Prodi at $\mathrm{S} 1$ level

1) Mechanical Engineering

2) Electronics Engineering

3) Industrial Management Engineering

4) Hydro Oceanography Technique

b. Prodi at D3 level

1) Mechanical Engineering

2) Electronics Engineering

3) Informatics Engineering

4) Hydro Oceanography Technique

In the next test, we will test the user application on the title display of the student work. This display will provide a brief description of the research title and display some photos of the research made. The following is a display of student work according to the research title being made.
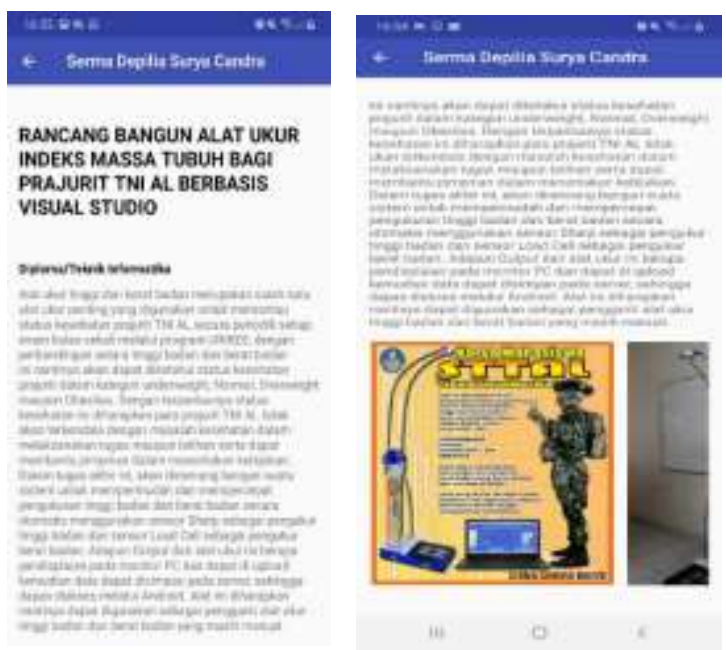

Figure 4.4 College Product Display 
At the next test the writer will test the user application on the QR Code scan feature. The camera icon in the lower right corner of the student work list is used to scan the QR Code in the student research tool. The purpose of scanning the QR Code on the displayed tool is to view more information such as video tutorials on how the tool works, tutorial documents, writing journals, etc. The following is an image of the QR Code scanning process on the student work tool.

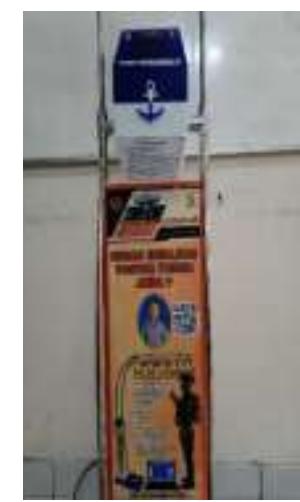

Gambar 4.2 Camera Scan Display

\section{CONCLUSIONS AND SUGGESTIONS}

\subsection{Conclusions}

Based on the results of the tests that have been carried out on the design of the WebBased STTAL Product Information System and Student Research, the following conclusions are obtained:

a. Can input, edit, and delete and display data on STTAL student final assignments periodically through the information system that has been created.

b. Can display STTAL student final project data according to the results of the final project that has been made, so that it can help the Head of Study Program in comparing the title of the final project submitted by final year students.

c. Able to help facilitate exhibition attendants in delivering information on the work of STTAL students to users, in this case exhibition visitors and work visit guests at STTAL.

\subsection{Suggestions}

In this study, there are several things that can be developed in order to get maximum results in the future, including:

a. This research must be further developed so that it can become an applied information system research, so that it can be fully used for the management of information on the work of
STTAL students aimed at visitors so that they can easily and quickly get information about the students' work on display.

b. In order for each student to match the title of the final project that has been made, they are required to make a video about how the tool works. The more videos that are displayed will increase the interest of visitors to see the information system of STTAL students' final assignments and research products.

c. To facilitate the installation of applications to users, it is hoped that the application can be registered on the Google Play store. So that if there is a user exhibition event, just download the application via Google Play store.

\section{ACKNOWLEDGEMENT}

The authors greatly acknowledge the support from Naval Technology College, STTAL Surabaya Indonesia for providing the necessary resources to carry out this research work. The authors are also grateful to the anonymous reviewers and journal editorial board for their many insightful comments, which have significantly improved this article.

\section{REFERENCES}

Alatas, H. (2011). Desain Penelitian DasarDasar Metodologi Penelitian Klinis. Jakarta: Sagung Seto.

Andarias Briyanto, R. (2015). Rancang Bangun Sistem Informasi Perpustakaan STTAL. Surabaya: Sekolah Tingi Teknologi Angkatan Laut.

Lani Sidharta. (1996). Internet Informasi Bebas Hambatan 2. Jakarta: Media Elek Komputindo. 